\title{
Behaviour of Exoskeleton Structures under Wind Loading
}

\author{
Dhilip Kumar R. G., Divya M.
}

\begin{abstract}
Tall buildings structural system has evolved a lot in recent times. Nowadays, a new system is being in the building as two parts namely exterior system and interior core. The exterior system will be located in the perimeter of the structure whereas the inner core located at the center which mainly accounts for the transfer of gravity load and the exterior system takes care of lateral loads rather than gravity load. The exterior shell is nothing but a diagonal grid which are effective as both gravity and lateral support to the tall buildings and this structural system is named as Exoskeleton. This exoskeleton diagrid structures imparts greater stiffness and lateral stability to the slender tall buildings. The objective of this study is to obtain a shape efficient lateral load resisting exoskeletal system using diagrid elements. Hence, the steel exoskeleton structures are analysed separately for both wind and seismic loads using ETABS 2015. 72-story structure with plan area of $2500 \mathrm{~m}^{2}$ adopted with different base plan (octagonal, rectangular and triangular shapes) with aspect ratio less than 5 has analyzed and designed. Gust factor method is adopted for wind loading since the tall structure undergoes vibration for various acceleration of the wind. The Gusts factor various from 1.19 to 2.11 in the design. Several analytical studies were conducted for different base plan with various diagrid angles and then this paper focus on obtaining a shape effective structure with optimal diagrid angles say 55.5, 65.7, 77.8 degree under adverse loading condition. Moreover, this work is done by considering following parameters say interstory drift, shear absorbing performance, the behaviour of inner core and outer shell.
\end{abstract}

Keywords: Aspect Ratio, Base shear, Diagrid Structure, Gust factor method, Story drift.

\section{INTRODUCTION}

The rapid urbanization puts constant pressure on limited land spaces which have considerably influenced the construction industries. The very high cost of land drives the industries to look up for vertical extension rather than horizontal crawling. The vertical extension of the building requires various design consideration that has to be incorporated. The building with less storey exhibit rigid behaviour rather the tall buildings are highly flexible. This flexibility can be measured by drift of the building.

When the height of the building increases the lateral load

Revised Manuscript Received on December 30, 2019.

* Correspondence Author

Dhilip Kumar R. G., Assistant Professor, Department of Civil Engineering, R.M.K. Engineering College, Kavaraipettai (Tamil nadu) India. E-mail: rgd.civil@rmkec.ac.in

Divya M., Research Scholar, Department of Civil Engineering, National Institute of Technology, Trichy (Tamil nadu) India.

E-mail: 403117052@nitt.edu

(C) The Authors. Published by Blue Eyes Intelligence Engineering and Sciences Publication (BEIESP). This is an open access article under the CC BY-NC-ND license (http://creativecommons.org/licenses/by-nc-nd/4.0/) resisting system has to be provided along with the gravity load carrying system. One of the up trending field in imparting high lateral stiffness to the building is exoskeletal structures. Exoskeleton structures are buildings that are supported by a members that exists outside of the primary enclosure, thus being expressed on the exterior of the building. Diagrid are the typical example of the exoskeleton structures since the diagonal members are situated in the building façade to transmit both the gravity and lateral loads to the substructure, by their well-defined system of triangulation of beams that may be of straight or curved and horizontal rings. These diagrid members may be of any materials say concrete, steel, timber, etc. which are articulated to form a complex system of diagonal members with optimized diagrid angles.

Diagrid is one such form of truss yet it is an upgraded idea of braced tube structure. In braced tubes the lateral stiffness is provided by the bracings but in diagrid structures the diagonal members provides maximum bending resistance and rigidity. In one way or the other it resembles the braced tubes yet it imparts greater advancement in the performance and design. The mega-diagonal members in the diagrid structures are widely spread to cover the entire building facade so as to eliminate the conventional vertical columns in the structure to provide greater lateral stiffness. The stiffness of the diagrid elements in lateral direction is much required not only for the static loads but also for the dynamic loads. This lateral stiffness provides greater resistance in both leeward and windward direction. The lateral motion in leeward side is mainly because of vertex shredding. This phenomenon occur mostly in leeward direction rather in windward direction.

Another critical condition which commonly occur in structure is Lock in condition. This condition mainly occur in stiffer building since stiffer building will have very high frequency. But diagrid structure will have impeccable stiffness due to its diagonal members. This very high stiffness lead to very high frequency which will be highly impossible to occur in practical condition hence it will be very difficult for such condition to occur in diagrid members thus leading to a resistance design for that.

\section{DIAGRID ANGLE}

The diagrid, the geometry of every single modulus majorly influences the load transferring mechanism. The movement of stories in building. It governs global shear, bending rigidity, internal axial force distribution. The diagrid module is of diamond in shape and they are classified in to four major categories. 
They are small modules (2-4 stories), mid-size modules (6-8 stories), large modules (more than 10 stories) and irregular modules. And also a major role is played by the angle between the diagonal members in establishing greater stiffness to the buildings. The structural design of diagrid structures with only diagonal members is substantially influenced by the angle of diagonals. The optimized diagrid angle have to be chosen for reduced material usage in the structure. The best suited angle for the column to effectively resist the bending is $90^{\circ}$ while $35^{\circ}$ for maximum shear resistance. Thus the optimal range for the diagrid element to effective resist both will lie between this ranges. In diagrid structures, the steeper diagrid angles towards the building corner provides greater bending rigidity. The short buildings of low aspect ratio behave like a shear beams and sky scrapers with very high aspect ratio behaves like bending beams. Fig.1. shows 8 storey diagrid with 60 degree diagrid angle.

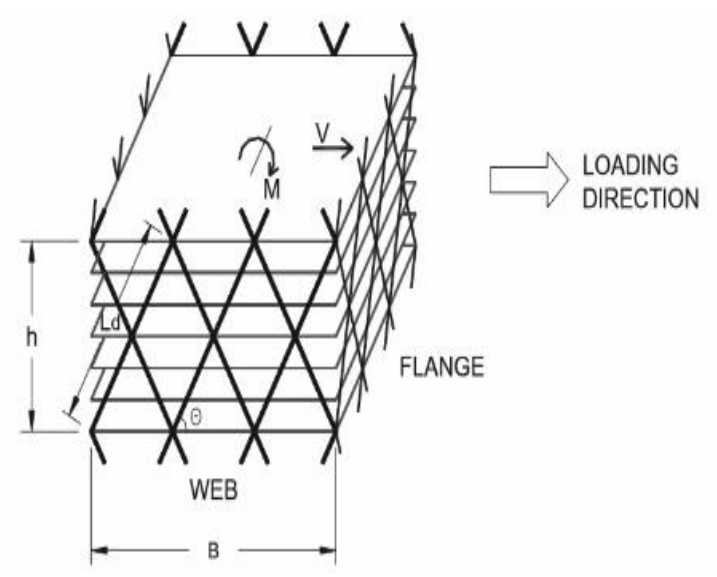

Fig 1: 8 storey diagrid with 60 degree diagrid angle

The diagrid transfers the gravity load by the triangulated diagonal members as that of like truss elements and these diagonal members imparts greater redundancy. Thus forms a efficient gravity load transfer. The lateral loads are mainly transferred by the moment transfer to the diagonal members, the flange members under go either a full compression or full tension whereas the web members undergo compression at the face which is nearer to the flange undergoing compression and tension near the flange undergoing tension. In shear loading the members that transfers the load is mainly the web members, this loading is transferred by the compression of one member and tension of other member in the same module. The diagrid members also undergoes non-apex loading at the interface between the members and the stories.

\section{LITERATURE REVIEW}

Kyoung sun moon et al (2011), studied the variation of geometric design of diagrid and its influences on the behavior of structure. In this study, a 60 storey building with a typical dimension of $36 \times 36 \mathrm{~m}$ with $18 \times 18 \mathrm{~m}$ inner core is considered. They studied three different types of diagrid arrangement such as twisted, tilled and free form towers for the above mentioned structure and also they studied the performance and efficiency of the variations adopted. A detailed parametric studies has been done by changing angle of tilting, rate of twisting, and density of diagrid at varies level of the structure. They concluded the study with following outcome that the top storey drift of the structure with tilled arrangement shows less displacement rather than other types.

Khushbu Jania et al (2013), made a study on structural design of tall building is governed by lateral loads due winds and gravity load. These loads are resisted by interior or exterior structural systems. They analyzed and designed a 36 storey diagrid building with regular floor plan of $36 \mathrm{x} 36 \mathrm{~m}$. The analysis and modelling are done using ETABS software. The diagrid angle is kept uniform. The interior frame is designed only for gravity load. The loading along and across winds are considered. They studied the behaviour of different storied buildings and compared the performance in terms of time period, top storey displacement and inter storey drift. From this study, it is clearly understood that the lateral loads are taken care by diagrid elements and the gravity loads are taken by internal column or internal core of the building. From these points, it is evident that the internal columns should be designed only for gravity loads and diagrids can be designed for lateral loads occurring to the system.

Kyoung sun moon et al (2014), proposed a methodology for preliminary design of the diagrid structure by considering the optimal angle, corner column and lateral stiffness of the diagrid for various height of the building. The diagrid angle is varied for 60, 42 and 20 storey building at two different scenario, considering corner column and not considering it. For the building of aspect ratio ranging from 5 to 7 while the lesser aspect ratio is not considered because their performance is affected by strength of the building. It is concluded that decrease in aspect ratio decreases the optimal diagrid angle by $10^{\circ}$ because the influence bending to lateral displacement is decreased as the height of the building decreased.

\section{DESIGN OF STRUCTURE}

In this paper, a 72 storey height building of $2500 \mathrm{~m}^{2}$ plan area adopted for the diagrid structure of three different base plan, say rectangular, octagonal and triangular because of their geometrical stability. There are three different types of module are adopted between the angle of maximum bending and shear rigidity. These modules encloses two, three and four storey. The diagrid angles adopted for rectangular base plan structure are $55.5^{\circ}, 65.15^{\circ}$ and $70.85^{\circ}$, for octagonal structure $57.76^{\circ}, 67.77^{\circ}$ and $72.5^{\circ}$, for triangular structure $53.33^{\circ}, 63.60^{\circ}, 69.58^{\circ}$. This condition are applied for two cases - with and without corner columns and it is impaired to quantify stiffness offered by the corner columns to the structure. The internal core of the building is $25 \%$ of the total area of the building and the beam spans about $5 \mathrm{~m}$ in spacing of $9 \mathrm{~m}$. The thickness of floor slab is taken as $100 \mathrm{~mm}$ and the height of the storey is $3.6 \mathrm{~m}$.

Published By: 
The dynamic loading offered by the wind in the windward direction is calculated by Gust factor method according to IS: 875(III)-1987. The finite element based software ETABS is used to model, analysis and design of this structure.

The supports are assumed to be fixed. The static and dynamic analysis is done by assuming the column element as truss elements. The typical plan of octagonal, square and triangular structures is shown in Fig.2, Fig.3 and Fig.4 respectively.

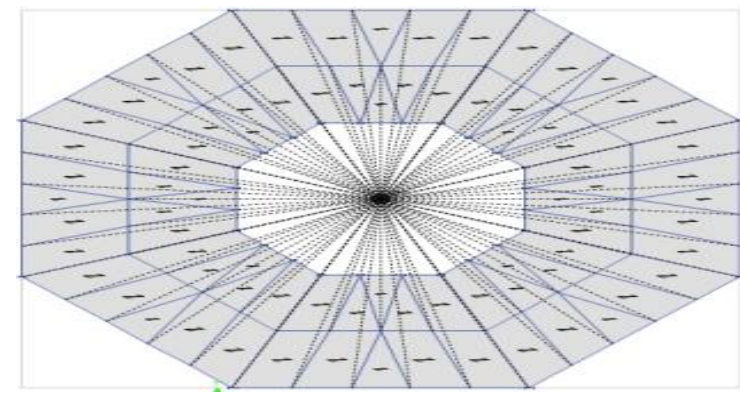

Fig.2. Octagonal plan with diaphragm

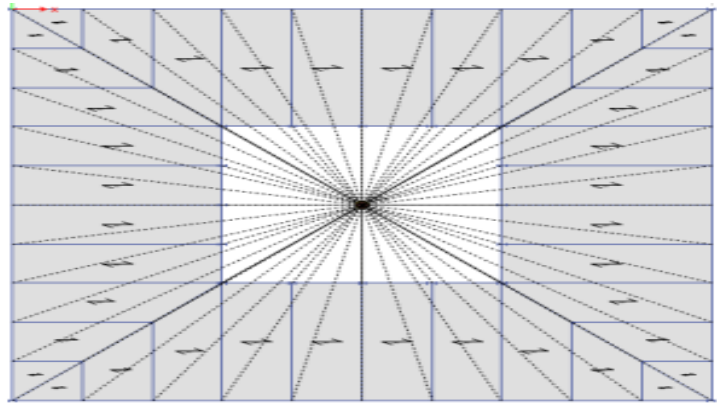

Fig.3. Square plan with diaphragm

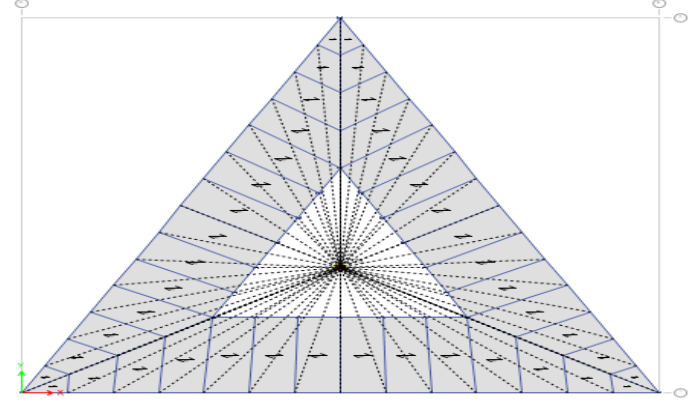

Fig.4. Triangular plan with diaphragm

Based on the direction of loading, the faces act as either web or flanges plane. The diagrids are assumed to be pin ended. Hence, the complexity is reduced by simply calculating the cross sectional properties of the members rather than calculating any flexural properties. The flexural properties may lead to the determination of various nonlinear parameters which is avoided completely. Therefore, the members can be designed only for the axial forces.

The diagrid members are assumed to be pin ended. So that they will be subjected to only axial forces and transverse shear forces. Diagrids members are assumed to be in flange plane or web plane and it is based on the direction of loading subjected by the member. This idealization of pin ended members greatly reduces the analyses burden since this assumption totally neglects the flexural activity of the member thus it also avoids secondary effects due to it.

The design methodology proposed by Moon et al (2007) directly calculates the member dimensions required to be incorporated. They limited the maximum lateral displacement to be $0.52 \mathrm{~m}$. They proposed a formula which accounts the number of diagrids on each plane accounts of shear force, moments, diagrid length, bending rigidity, curvature, width of the building.

Tall structures are then analysed by considering it as cantilever beam from the ground. Then, the deflection at the top, is given by Connor (2003) which is overall summation of product between transverse shear strain and height to the building along with the product of curvature and squared product of height of the building. The maximum overall deflection of the building is generally assumed to be 500 by the height of building.

\section{NUMERICAL INVESTIGATION}

The wind load and gravity loads are combined and assigned to the structure in ETABS software. From the results taken from it, the members are designed as per IS 800-2007. The yield strength of the steel is taken as 345 $\mathrm{N} / \mathrm{mm}^{2}$. The sizes of the typical diagrid members selected are for the first 19 stories, $825 \mathrm{~mm}$ pipe section with $50 \mathrm{~mm}$ thickness, from $20^{\text {th }}$ storey to $36^{\text {th }}$ storey $675 \mathrm{~mm}$ pipe sections with $50 \mathrm{~mm}$ thickness., from $37^{\text {th }}$ storey to $50^{\text {th }}$ storey $750 \mathrm{~mm}$ pipe section with $25 \mathrm{~mm}$ thickness, from $50^{\text {th }}$ storey to $60^{\text {th }}$ storey $525 \mathrm{~mm}$ pipe section with $25 \mathrm{~mm}$ thickness, from $60^{\text {th }}$ storey to $70^{\text {th }}$ storey $450 \mathrm{~mm}$ pipe section with $25 \mathrm{~mm}$ thickness, from $70^{\text {th }}$ storey to $80^{\text {th }}$ storey $375 \mathrm{~mm}$ pipe section with $12 \mathrm{~mm}$ thickness.

And for all stories, ISWB 600 is used for the beam section with a plate section of $25 \mathrm{~mm}$ placed on the top and bottom of the member. The internal columns adopted are $2200 \mathrm{~mm} \mathrm{x}$ $2200 \mathrm{~mm}$ up to $19^{\text {th }}$ storey and $2000 \mathrm{~mm}$ x $2000 \mathrm{~mm}, 1800$ $\mathrm{mm}$ x $1800 \mathrm{~mm}, 1650 \mathrm{~mm}$ x $1650 \mathrm{~mm}, 1500 \mathrm{~mm}$ x $1500 \mathrm{~mm}$ (from $20^{\text {th }}$ storey to $80^{\text {th }}$ storey) to the above mentioned storey for the change of diagrid members.

\section{RESULT AND DISCUSSION}

The taller building exhibits more like bending beam so it has to be designed more for flexural action and it shows more bending deformation. The short building behaves more like a shear beam. The time period of the buildings are given in Table I

Table-I: Time period

\begin{tabular}{|c|c|c|}
\hline Square base & $\begin{array}{c}\text { Octagonal } \\
\text { base }\end{array}$ & Triangular base \\
\hline $\mathrm{X}$ direction $=3.29$ & $\mathrm{X}$ direction $=$ & $\mathrm{X}$ direction $=$ \\
$\mathrm{s}$ & $3.15 \mathrm{~s}$ & $2.93 \mathrm{~s}$ \\
\hline $\mathrm{Y}$ direction $=3.29$ & $\mathrm{Y}$ direction $=$ & $\mathrm{Y}$ direction $=$ \\
$\mathrm{s}$ & $3.15 \mathrm{~s}$ & $2.89 \mathrm{~s}$ \\
\hline
\end{tabular}

The force coefficient of the buildings are $\mathrm{Cf}_{\mathrm{x}, \mathrm{y}}$ (square) $=$ $1.75, \mathrm{Cf}_{\mathrm{x}, \mathrm{y}}$ (octagonal) $=1.2, \mathrm{Cf}_{\mathrm{x}}$ (triangular) $=1.297$ (loading along base of the triangle) $\mathrm{Cf}_{\mathrm{y}}$ (triangular) $=0.866$ (loading along apex of the triangle). These buildings are assumed to be situated at the location which is under category IV (terrain with numerous large closely spaced obstruction above $25 \mathrm{~m}$ ).

Published By:

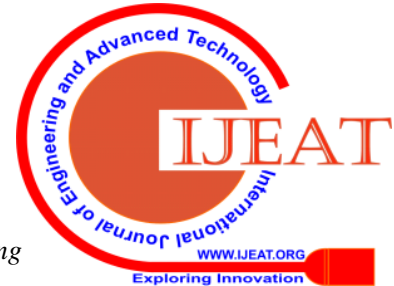


The background factors are 0.1607 square base, 0.1732 for octagonal base and 0.42 for triangular base in both the direction. The size reduction factor ranged from 0.0125 to 0.07 for square base, 0.02 to 0.073 for octagonal base and 0.005 to 0.047 for triangular base. The gust factor ranges from 1.911 to 2.167 for square base, 1.937 to 2.087 for octagonal base and 1.630 to 1.792 for triangular base. The shear force for every 10 storey is given in Table II. These loads are applied to the center of diaphragm. The analyze of load combination as specified in IS 875 (III) - 1987. The top storey displacement undergone by square, octagonal and triangular structures are listed in Table III, Table IV and Table V respectively.

Table-II: Shear force

\begin{tabular}{|c|c|c|c|c|}
\hline \multirow{2}{*}{$\begin{array}{c}\text { Storey } \\
\text { Number }\end{array}$} & Square & Octagonal & \multicolumn{2}{|c|}{ Triangular } \\
\cline { 2 - 5 } & $\begin{array}{c}\text { In } \mathbf{x , y} \\
\mathbf{( k N )}\end{array}$ & In $\mathbf{x , y ~ ( k N )}$ & $\begin{array}{c}\text { In } \mathbf{x} \\
\mathbf{( k N )}\end{array}$ & $\begin{array}{c}\text { In y } \\
\mathbf{( k N )}\end{array}$ \\
\hline $10^{\text {th }}$ & 150.33 & 103.08 & 103.21 & 158.66 \\
\hline $20^{\text {th }}$ & 281.66 & 193.13 & 193.43 & 292.48 \\
\hline $30^{\text {th }}$ & 369.90 & 253.64 & 253.84 & 384.16 \\
\hline $40^{\text {th }}$ & 471.65 & 323.41 & 325.3 & 278.78 \\
\hline $50^{\text {th }}$ & 506.30 & 347.17 & 342.73 & 526.05 \\
\hline $60^{\text {th }}$ & 564.53 & 387.10 & 386.89 & 559.48 \\
\hline $70^{\text {th }}$ & 622.2 & 426.65 & 426.89 & 616.15 \\
\hline
\end{tabular}

Table-III: Square base Top storey displacement

\begin{tabular}{|l|l|l|l|}
\hline $\begin{array}{c}\text { Diagrid } \\
\text { angle }\end{array}$ & Condition & $\begin{array}{l}\text { Top storey } \\
\text { displacemen } \\
\text { t }\end{array}$ & $\begin{array}{c}\text { Targeted } \\
\text { displacemen } \\
\text { t }\end{array}$ \\
\hline 55.55 & Column & 0.5110 & 0.5184 \\
\hline 55.55 & No column & 0.5199 & 0.5184 \\
\hline 65.15 & Column & 0.5101 & 0.5184 \\
\hline 65.15 & No column & 0.5199 & 0.5184 \\
\hline 70.85 & Column & 0.5195 & 0.5184 \\
\hline 70.85 & No column & 0.5273 & 0.5184 \\
\hline
\end{tabular}

Table-IV: Octagonal base Top storey displacement

\begin{tabular}{|l|l|l|l|}
\hline $\begin{array}{c}\text { Diagrid } \\
\text { angle }\end{array}$ & Condition & $\begin{array}{c}\text { Top storey } \\
\text { displacemen } \\
\text { t }\end{array}$ & $\begin{array}{c}\text { Targeted } \\
\text { displacemen } \\
\text { t }\end{array}$ \\
\hline 57.76 & Column & 0.5138 & 0.5184 \\
\hline 57.76 & No column & 0.5241 & 0.5184 \\
\hline 67.77 & Column & 0.5161 & 0.5184 \\
\hline 67.77 & No column & 0.5217 & 0.5184 \\
\hline 72.50 & Column & 0.5216 & 0.5184 \\
\hline 72.50 & No column & 0.5304 & 0.5184 \\
\hline
\end{tabular}

Table-V: Triangular base Top storey displacement

\begin{tabular}{|l|l|l|l|}
\hline $\begin{array}{c}\text { Diagrid } \\
\text { angle }\end{array}$ & Condition & $\begin{array}{l}\text { Top storey } \\
\text { displacement }\end{array}$ & $\begin{array}{l}\text { Targeted } \\
\text { displacement }\end{array}$ \\
\hline 53.33 & Column & 0.5161 & 0.5184 \\
\hline 53.33 & No column & 0.5192 & 0.5184 \\
\hline 63.60 & Column & 0.5012 & 0.5184 \\
\hline 63.60 & No column & 0.5194 & 0.5184 \\
\hline 71.58 & Column & 0.5102 & 0.5184 \\
\hline 71.58 & No column & 0.5203 & 0.5184 \\
& & & \\
\hline
\end{tabular}

The effect of column and without considering column for square, octagonal and triangular structures is studied. The following results has been drawn based on the analysis.

1) It is highly clear that the buildings the optimum angle for the triangular structure is $63.60^{\circ}$, square is $65.15^{\circ}$, octagonal is $67.77^{\circ}$. And also buildings with triangular plan shows higher stiffness when compared to others. This is mainly because of the reduced coefficient of force that acts on the structure.

2) The triangular structure shows about $11.2 \%$ greater stiffness when compared to the other profiled structures.

3) The corner column produces greater stiffness to the structure. The column-less building requires about $10 \%$ more steel to counteract the deflection of building caused for the absence of column.

4) On considering the aesthetic appearance of the building and free office area, the column less condition can be adopted, yet that also deflects with the permissible limit for the optimal angle.

\section{CONCLUSION}

This paper mainly deals with 72 storey building analysis and design under three different structures with floor area of 2500 $\mathrm{m} 2$ is considered. ETABS software is used for modelling and analysis of structure. Load distribution in diagrid system is also studied. From the study it is well known that the structure with triangular base plan shows greater stiffness when compared to other. And also the optimal angles for considered structures are presented and their variations of response for different diagrid angles are also dealt in detail.

\section{REFERENCES}

1. Kyoung-sun moon, Jerome J.connor and John E. Fernandez, "Diagrid structural systems for tall buildings: characteristics and methodology for preliminary design"e, Structural Design of Tall Special Building,Vol.16., pp.205-230.,2007

2. Giulia milana, Pierluigiolmati, Konstantin's Gkoumas,Franco Bontempi, "Ultimate capacity of diagrid systems for tall buildings in nominal configuration and damaged state ${ }^{\text {ee }}$ Periodica Polytechnica Civil Engineering,Vol.59(3), pp. 381-391, 2015

3. Giovanni Mariamontuori, Elenamele, Giuseppeb Randonisio, Antonello De Luca "Secondary bracing systems for diagrid structures in tall buildingse Engineering Structures Vol.75, pp.477-488.,2014.

4. Giovanni Maria Montuori, Elena Mele, Giuseppe Brandonisio, Antonello De Luca "Geometrical patterns for diagrid buildings: Exploring alternative design strategies from the structural point of viewee, Engineering Structures Vol.71, pp.112-127, 2014.

5. Nishith B. Panchal1, Vinubhai R. Patel "Diagrid structural system: strategies to reduce lateral forces on high-rise buildings international journal of research in engineering and technologyee, Procedia Engineering Vol.25, pp.142-149.,2014

6. Kyoung sun moon "Diagrid structures for complex-shaped tall buildings" Procedia Engineering Vol.14, pp.1343-1350., 2014.

7. Ali, M. M. and Moon K. "Structural Developments in Tall Buildings: Currents Trends and Future Prospects ${ }^{\text {ee }}$. Architectural Science Review, Vol.50.3, pp.205-223., 2007.

8. Sepideh Korsavil and Mohammad Reza Maqhareh,,"The Evolutionary Process of Diagrid Structure towards Architectural, Structural and Sustainability Concepts: Reviewing Case Studiese Architectural Engineering Technology Vol.3 pp.2-6., 2014

9. IS: 456-2000. Plain and Reinforced Concrete- Code of Practice (Fourth Revision), Bureau of Indian Standard, New Delhi.

10. IS: 1893(Part-I)-2002, Criteria for Earthquake Resistant Design of Structures, Bureau of Indian Standard, New Delhi. 


\section{AUTHORS PROFILE}

Dhilip Kumar R. G. is Assistant Professor, Department of Civil Engineering, R.M.K. Engineering College. He obtained his M.E Structural Engineering from PSNA College of Engineering \& Technology, Dindigul. He has published papers in international and National Journals. He is a life time member of professional societies ISTE.

Divya M. is Research Scholar, Department of Civil Engineering, National Institute of Technology, Trichy. She obtained her M.E. Structural Engineering from PSNA College of Engineering \& Technology, Dindigul. She has published papers in international and National Journals. 